\section{ОСОБЕННОСТИ ПРЕПОДАВАНИЯ ТУВИНСКОГО ЯЗЫКА В ТУРЦИИ}

\section{ISSUES OF TEACHING TUVAN LANGUAGE IN TURKEY}

\section{Маргарита Б. Кунгаа}

Тувинский институт гуманитарных

и прикладных социально-

экономических исследований, Российская Федерация

\author{
Margarita B. Kungaa \\ Tuvan Institute for Humanities \\ and Applied Socio-Economic Studies, \\ Russian Federation
}

Тувинский язык преподается и изучается не только в Туве. Он, наряду с другими тюркскими языками, преподается в ряде университетов Турции. Основная особенность состоит в том, что тувинский язык, как и другие тюркские языки, преподается турецким студентам не как иностранный, а родственный их родному языку язык. Автор статьи, основываясь на своем опыте преподавания тувинского языка и литературы в Университете Анкары (1997-2003 22.), делится своими наблюдениями по поводу проблем, которые встречаются в преподавании тувинского языка турецким студентам.

В Турциии исходят из понимания, что все тюркские языки восходят к единому языку-основе - пратюркскому. Поэтому они рассматриваются абсолютным большинством специалистов в области тюркологии как диалекты этого языка-основы, студенты изучают тюркские языки не как иностранные, а как родственные своему родному языку языки. В стране насчитывается около 20 университетов, где преподаются разные тюркские языки.

Специалистов по тувинскому языку - исследователей и педагогов - в настоящее время в Турции немало. Однако студенты изучают тувинский

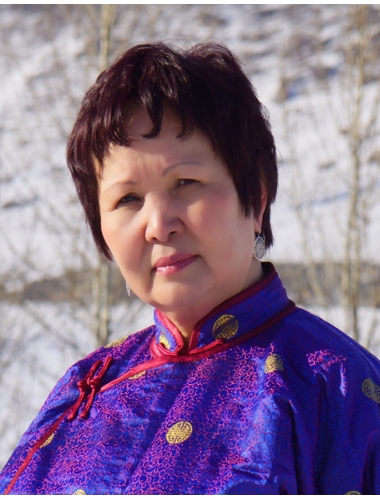

Tuvan language is taught and studied both in the Republic of Tuva and beyond its borders. Alongside with other Turkic languages, it is taught at a number of universities in Turkey - and like all languages belonging to the same group, it is taught to Turkish students not as a foreign, but as a cognate tongue. Speaking from her own experience as lecturer in Tuvan language and literature at the University of Ankara (1997-2003), the author shares her opinions on the issues language instructors frequently face when teaching Tuvan to Turkish students.

Since all Turkic languages are understood to stem back to a single ancestor - Proto-Turkic language, the absolute majority of Turkologists see them as dialects of this ancestor tongue. Correspondingly, in their learning experience Turkish students distinguish between foreign languages and those cognate to their mother tongue. Overall, about 20 Turkish universities offer courses in various Turkic languages.

At the moment, quite a lot of specialists in Tuvan - both researchers and educators - work in

Кунгаa Маргарита Базыр-ооловна - кандидат педагогических наук, ведущий научный сотрудник сектора фольклора Тувинского института гуманитарных и прикладных социально-экономических исследований. Адрес: 667000, Россия, г. Кызыл, ул. Кочетова, д. 4. Тел./факс: +7 (394-22) 2-39-36. Эл. адрес: m.b.kungaa@mail.ru

Kungaa Margarita Bazyr-oolovna, Candidate of Pedagogy, Leading Researcher, Sector of Folklore, Tuvan Institute of Human and Applied Socio-Economic Studies. Postal address: 4, Kochetova Str., 667000, Kyzyl, Russian Federation. Tel.: +7 (394-22) 2-39-36. E-mail: m.b.kungaa@mail.ru 
язык не слишком охотно. Есть проблема в мотивации. Они не видят перспектив дальнейшей профессионализации, кроме как стать ученымисследователем. Другая проблема - отсутствие учебников, учебных пособий, тувинско-турецких и турецко-тувинских разговорников, способствующих изучению турецкими студентами тувинского языка на должном уровне. Проблема эта не решена до сих пор.

Для турецких студентов изучение тувинского языка - перспектива стать тюркологом. А с точки зрения интересов Тувы, наличие таких специалистов, способствовало бы популяризации тувинской культуры, имело бы перспективы сотрудничества Тувы с Турцицей в области науки, культуры, экономики в рамках развития российско-турецких отношений.

Ключевые слова: тюркский язык; тувинский язык; турецкий язык; проблемы преподавания; Турция
Turkey. However, there is a marked lack of student motivation to study Tuvan. Students see little incentives of professional career growth except becoming an academic linguist. Another notable issue is the absence of textbooks, study manuals, or Tuvan-Turkish and Turkish-Tuvan phrasebooks which could facilitate achieving the required level of command of Tuvan by Turkish students. This problem as yet remains unsolved.

For Turkish students, learning Tuvan opens the prospect of becoming a Turkologist. For the Republic of Tuva, the presence of such specialists would help popularize Tuvan culture and enhance collaboration between Tuva and Turkey in the areas of science, culture and economy. This will also help develop the relations between Turkey and Russian Federation.

Keywords: Turkic language; Tuvan language; Turkish language; issues of language teaching; Turkey

\section{Введение}

Моя педагогическая практика как бывшего вузовского преподавателя в основном связана с преподаванием тувинской литературы и методики её преподавания в национальной (тувинской) школе. Я работала на кафедре тувинского языка и литературы Кызылского госпединститута и Тувинского госуниверситета в первые годы после его образования. Но был и опыт преподавания тувинского языка в разных аспектах и в разных условиях.

Например, в конце 1980-х - в начале 1990-х годов, мне довелось вести, как, впрочем, и другим преподавателям кафедры, курсы тувинского языка для невладеющих им. Например, для работников Кызылского городского комитета ВЛКСМ во главе с тогдашним первым секретарем Ю. Ю. Ананьиным; для преподавателей физико-математического факультета Кызылского госпединститута и других коллективов г. Кызыла. Среди слушателей тех курсов были и те, кто родился в интернациональной семье, вырос в городе и не владел тувинским языком.

Основным подспорьем в этой работе был «Учебник тувинского языка», разработанный старшим преподавателем кафедры тувинского языка и литературы Кызылского пединститута, языковедом Е. Б. Салзынмаа и предназначенный для студентов русской группы филологического факультета названного вуза (Салзынмаа, 1980) и «Русско-тувинский разговорник», составленный этим же автором и изданный в 1991 г. уже в третьем, дополненном варианте (Салзынмаа, 1991). В том же году в дополнение к вышеназванным работам появилось пособие под названием «Поговорим по-тувински», написанное К. А. Бичелдеем и состоящее из 20 уроков на разные темы (Бичелдей, 1991). Все эти работы ак- 
тивно использовались мною и моими коллегами при ведении курсов тувинского языка для русскоязычных.

В связи с тем, что в 1990-е годы в Туву стали приезжать, хоть и не так много, как сейчас, иностранцы, в том числе ставившие перед собой цель изучить тувинский язык, а за помощью они обращались в основном к преподавателям кафедры тувинского языка и литературы, нами понемногу приобретался и опыт преподавания тувинского языка как иностранного. Моей первой ученицей в этом плане стала Кира ван Дузен (Kira van Deusen), которая впоследствии перевела на английский язык некоторые тувинские народные сказки и опубликовала их отдельным сборником в Америке (Deusen, 1996).

Еще один мой опыт - преподавание тувинского языка и литературы студентам факультета языка и исторической географии Университета Анкары, куда я приехала в 1997 г. по приглашению заведующей кафедрой современных тюркских языков и литератур, профессора Семы Барутджу Озондер. По ее инициативе в 1992 г. там была открыта первая в Турции кафедра подобного направления. Для преподавания тувинского языка тогда был приглашен кандидат филологических наук Ч. М. Доржу, обучавшийся в то время в докторантуре Института языкознания РАН (г. Москва). После его отъезда в 1994 г. в Туву, тувинский язык там стала преподавать М. В. Бавуу-Сюрюн, недавно защитившая диссертацию на степень доктора филологических наук. Она была приглашена для участия в проекте Турецкого лингвистического общества «Сравнительная грамматика тюркских языков».

Начиная с 2004 г., тувинский язык на данной кафедре преподает Гюльсум Килли Йылмаз, начавшая еще во второй половине 1990-х годов изучать хакасский язык, а также, наряду с ним, тувинский. Ныне она признанный специалист по этим и другим сибирским тюркским языкам, профессор.

В настоящей статье мы, основываясь на своих опыте преподавания (в течение шести полных учебных годов) тувинского языка и литературы в Университете Анкары, отметим основные проблемы, которые встречаются в преподавании тувинского языка турецким студентам. Но сначала вкратце остановимся на преподавании и исследовании тюркских языков в Турции, отметим их специфику в общих чертах.

\section{Особенности преподавания и исследования тюркских языков в турциии}

В Турции исходят из понимания, что все тюркские языки восходят к единому языку-основе - пратюркскому. Поэтому они рассматриваются абсолютным большинством специалистов в области тюркологии как диалекты этого языкаосновы. Не вдаваясь в научные и другие аспекты и подробности данного во- 
проса, отметим лишь то, что кафедры, учебные планы которых включают преподавание тюркских языков, называются «Çağdaş Türk Lehçeleri ve Edebiyatları», что буквально переводится как «Современные тюркские диалекты и литературы». Поэтому студенты, которые учатся на разных отделениях этих кафедр и по окончании учебы получают дипломы с квалификацией «Тюрколог», изучают не иностранные, а родственные своему родному языку языки. Учебные планы кафедр охватывают такие предметы, как язык, литература, история и культура разных тюркских народов.

Например, кафедра современных тюркских языков и литератур факультета языка и исторической географии Университета Анкары имеет пять отделов:

1) отдел юго-западных (огузских) тюркских языков и литератур. Здесь изучаются языки, литературы, истории и культуры азербайджанцев, туркмен, гагаузов, халаджов и хорасанских тюрков, а также анатолийских турков в Турции;

2) отдел юго-восточных тюркских языков и литератур. Здесь изучаются языки, литературы, истории и культуры узбеков, уйгур, саларов, желтых уйгуров;

3) отдел северо-западных (кипчакских) тюркских языков и литератур. Здесь изучаются языки, литературы, истории и культуры казахов, кыргызов, татар Республики Татарстан РФ, башкир, а также крымских татар, каракалпаков, карачаево-балкаров, кумуков, ногайцев и караимов;

4) отдел северо-восточных (сибирских) тюркских диалектов и литературы. Здесь изучаются языки, литературы, истории и культуры алтайцев, тувинцев, хакасов, саха (якутов) и шорцев;

5) отдел чувашского тюркского языка и литературы. Здесь преподаются язык, литература, история и культура чувашей.

Аналогичную структуру имеют кафедры современных тюркских языков и литератур и других университетов Турции. Обобщенно можно отметить, что научные исследования на кафедрах ведутся в основном в сравнительно-сопоставительном ключе на основе методов исторического познания (историко-генетического, историко-сравнительного, историко-типологического, историкосистемного методов и метода диахронического анализа).

В настоящее время насчитывается около 20 турецких университетов, где студентам преподаются, в обязательном порядке и выборочно по желанию, разные тюркские языки. По окончанию вуза воспитанники этих кафедр устраиваются работать в разные места, но самые успешные и талантливые в овладении тюркскими языками нередко становятся учеными-исследователями, в том числе тувинского языка.

В настоящее время в Турции специалистов, знающих, в той или иной мере, и исследующих, в том или ином аспекте, тувинский язык, немало. Это Экрем Арыкоглу из Университета Гази, Мехмет Олмез из Университета Йылдыз, 
Гюльсум Килли Йылмаз из Университета Анкары, Али Ылгын из Университета Стамбула, Вилдан Кочоглу из Университета Эге, Илкер Тосун из Университета Тракии и другие. Есть и молодые исследователи, которые занимаются изучением тувинского языка. Преподавание тувинского языка, его научное изучение со стороны турецких специалистов в области тюркологии, осуществление ими переводов и других работ, безусловно способствуют популяризации тувинского языка не только в Турции, но и во всем мире, содействуют его сохранению и развитию.

\section{Проблемы в обучении турецикх студентов тувинскому языку}

Самыми главными из них, на наш взгляд, являются проблемы мотивационного характера.

Как известно, мотивация - это основная движущая сила в изучении языков и т. д. В качестве примера можно привести зарубежных музыкантов, которые в настоящее время довольно часто приезжают в Туву с целью научиться исполнять горловое пение, и, осуществляя свою цель, специально учат тувинский язык. Что касается тех турецких студентов, которых мне довелось учить тувинскому языку и литературе, у них мотивация на изучение тувинского языка была слабой, несмотря на то, что предмет был для них обязательным. Как причина этого, конечно, не исключаются личностные качества человека, но она была больше в том, что они не видели перспективы, связанной со знанием тувинского языка, кроме как стать ученым-исследователем в области тувинского языка, фольклора, литературы. Но все понимали, что стать ученым-исследователем дано не каждому. Если сравнить, например, с казахским или кыргызским языками, то перспектив трудоустройства было и есть больше в силу того, что существуют совместные фирмы и т. д. Все же внутренняя мотивированность получить диплом о высшем образовании, который гарантировал студентам трудоустроиться в школы, в лицеи и т. д., мотивированность учиться, узнавать что-то новое вкупе с уважением к преподавателю помогала студентам преодолевать данное противоречие, сомнение.

В целях повышения мотивации в изучении турецкими студентами тувинского языка приходилось искать и другие выходы, прежде всего в заложенные в самом предмете и в его связях с турецким и другими тюркскими языками. Привлекались самые интересные и занимательные языковые, исторические, культурные факты и примеры, использовались разные методические подходы и приемы, формы работы. Например: сопоставление, сравнение, этимологический комментарий, работа со словарями, сборниками в целях поиска эквивалентов тувинских слов, выражений, в том числе пословичного характера, в турецком и других тюркских языках, перевод текстов, в том числе фольклорных и литературных произведений. 
Еще одна проблема, не менее значимая, - это отсутствие учебников, учебных пособий, тувинско-турецких и турецко-тувинских разговорников, способствующих изучению турецкими студентами тувинского языка на должном уровне. Проблема эта не решена до сих пор, и это, безусловно, плохо для освоения турецкими студентами тувинского языка, который хоть и является родственным их родному языку, но изучается вне тувинской языковой среды.

В 2003 и 2005 гг. в свет вышли два словаря: «Tuva Türkçesi sözlüğ̈̈» (Словарь тувинского языка), принадлежащий перу Экрема Арыкоглу и тувинского языковеда, кандидата филологических наук К. Б. Куулар (Доржу) и изданный в Турции (Арыкоглу, Куулар, 2003), а также «Тыва-түрк словарь. Tuvaca-Türkçe sözlük» (Тувинско-турецкий словарь), разработанный широко известным тувинским ученым-языковедом Д. А. Монгушом и изданный в Туве (Монгуш, 2005).

Первый из этих словарей является кратким вариантом «Тувинско-русского словаря», изданного в 1968 г. под редакцией Э. Р. Тенишева (Тувинско-русский словарь, 1968) и включает чуть более 8000 слов. Все тувинские слова даны в транскрипции на латинице. Смысловые значения слов ограничены основными значениями, что делает его недостаточным для работы с текстами, с художественными произведениями. То, что тувинские слова даны не на кириллице, а на латинице, тоже делает словарь «неудобным» в работе.

«Тувинско-турецкий словарь» Д. А. Монгуша включает более 9000 слов. Здесь, в отличие от первого словаря, тувинские слова даны на кириллице, а их эквиваленты в турецком языке - на латинице. В приложении к словарю автор-составитель в помощь тувинскому читателю разъясняет, показывая на примерах, основные черты и свойства фонетики, морфологии и других уровней турецкого языка.

В дополнение к этим словарям требуется создание новых, более расширенных как по составу (количеству) слов, так и по их значениям, включая переносные. Это тоже очень важно в условиях преподавания тувинского языка вне тувинской языковой среды.

\section{Заключение}

В силу того, что тувинский и турецкий языки, хоть и родственные, но в течение многих тысячелетий каждый из них имел свой путь развития, что обусловило достаточно большую разницу в лексическом составе, отличия в фонетике и в морфологии, тувинский язык осваивается турецкими студентами труднее, чем, например, языки огузской и даже кипчакской групп. Но все же их родственность и близость по многим параметрам служит фундаментом и фактором, помогающим успешному изучению турецкими студентами тувинского языка. 
Зачем турецким студентам, турецким специалистам тувинский язык? Как мы уже сказали, что для них он является частью их филологического образования, подготовки как тюркологов. Но мы бы хотели также взглянуть на этот вопрос с точки зрения потребностей Тувы, жителей Тувы. Наличие таких специалистов, во-первых, в целом способствовало бы популяризации тувинской культуры, имело бы перспективы сотрудничества Тувы с Турцией в области науки, культуры, экономики, разумеется в тех вариантах, которые взаимно обогащали бы стороны и способствовали в общем российско-турецким отношениям.

\section{СПИСОК ЛИТЕРАТУРЫ}

Арыкоглу, Э., Куулар, К. (2003) Tuva Türkçesi sözlüğü [Словарь тувинского языка]. Ankara : Türk Dil Kurumu. 118 c.

Бичелдей, К. А. (1991) Поговорим по-тувински : пособие для изучающих тувинский язык. Кызыл : Тув. кн. изд-во. 80 с.

Монгуш, Д. А. (2005) Тыва-түрк словарь. Tuvaca-Türkçe sözlük [Тувинско-турецкий словарь]. Кызыл : Тув. кн. изд-во. 590 с.

Салзынмаа, Е. Б. (1980) Учебник тувинского языка : для студентов русской группы филологического факультета Кызылского государственного педагогического института. Кызыл : Тув. кн. изд-во. 232 с.

Салзынмаa, Е. Б. (1991) Русско-тувинский разговорник. Кызыл : Тув. кн. издво. 114 c.

Тувинско-русский словарь (1968) : около 22000 слов / под ред. Э. Р. Тенишева. М. : Советская энциклопедия. 465 с.

Van Deusen, K. (1996) Shyaan am! Tuvan Folk Tales / selected and retold by K. Van Deusen. Washington, Belligham, Udahan Books. 47 p.

Дата поступления: 20.01.2018 г.

\section{REFERENCES}

Arykoglu, E. and Kuular, K. (2003) Tuva Türkçesi sözlüğ̈̈ [A Dictionary of the Tuvan Language]. Ankara, Türk Dil Kurumu. 118 p. (In Tuv. and Turkish).

Bicheldei, K. A. (1991) Pogovorim po-tuvinski : posobie dlia izuchaiushchikh tuvinskii iazyk [Let's Talk Tuvan: a Guide for Tuvan Language Learners]. Kyzyl, Tuv. kn. izd-vo. 80 p. (In Russ. and Tuv.).

Mongush, D. A. (2005) Tyva-tyrk slovar'. Tuvaca-Türkçe sözlük [A Tuvan-Turkish Dictionary]. Kyzyl, Tuv. kn. izd-vo. 590 p. (In Tuv. and Turkish). 
Salzynmaa, E. B. (1980) Uchebnik tuvinskogo iazyka : dlia studentov russkoi gruppy filologicheskogo fakul'teta Kyzylskogo gosudarstvennogo pedagogicheskogo instituta [A Textbook of Tuvan Language for Russian-Language Class of the Faculty of Philology, Kyzyl State Pedagogical Institute]. Kyzyl, Tuv. kn. izd-vo. 232 p. (In Russ. and Tuv.).

Salzynmaa, E. B. (1991) Russko-tuvinskii razgovornik [A Russian-Tuvan Phrasebook]. Kyzyl, Tuv. kn. izd-vo. 114 p. (In Russ. and Tuv.).

Tuvinsko-russkii slovar' [A Tuvan-Russian Dictionary] (1968): c. 22000 words / ed. by E. R. Tenishev. Moscow, Sovetskaia entsiklopediia. 465 p. (In Russ. and Tuv.).

Van Deusen, K. (1996) Shyaan am! Tuvan Folk Tales / selected and retold by K. Van Deusen. Washington, Belligham, Udahan Books. 47 p.

Submission date: 20.01.2018.

\section{Для цитирования:}

Кунгаа М. Б. Особенности преподавания тувинского языка в Турции [Электронный ресурс] // Новые исследования Тувы. 2018, № 1. URL: https://nit.tuva.asia/nit/ article/view/756 (дата обращения: дд.мм.гг.). DOI: 10.25178/nit.2018.1.6

\section{For citation:}

Kungaa M. B. Issues of Teaching Tuvan Language in Turkey. The New Research of Tuva, 2018, no. 1 [on-line] Available at: https://nit.tuva.asia/nit/article/view/756 (accessed:... ). DOI: $10.25178 /$ nit.2018.1.6 